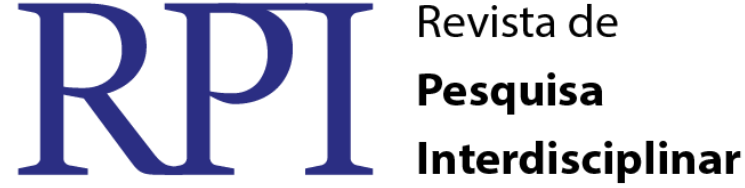

\section{AVALIAÇÃO DA APRENDIZAGEM dA LÍNGUA PORTUGUESA ESCRITA PARA SURDOS: UM DESAFIO ESCOLAR.}

\author{
Maria Geane de Lima Ferreira ${ }^{1}$-UFPB
}

\begin{abstract}
RESUMO
Este artigo tem como objetivo a discussão da escrita de alunos surdos na Língua Portuguesa e as possíveis estratégias utilizadas para que esta não se torne uma ferramenta de exclusão, como também conhecer e analisar as práticas de ensino da Língua Portuguesa para esses alunos, explicitando as possibilidades e dificuldades vividas no processo no processo de ensino e aprendizagem da Língua Portuguesa por estes alunos e seus professores. Podendo utilizar possíveis metodologias, respeitando e entendendo o sujeito surdo e suas diferentes identidades. Serão abordados aspectos relevantes sobre a educação dos surdos em relação à avaliação da Língua Portuguesa em sua modalidade escrita, para o desenvolvimento escolar dos alunos surdos. Tendo como eixo de pesquisa a Constituição Federal de 1988 a qual fala que todos tem direito a educação (Brasil, 1988), Lei 10.436/02 que dispõe sobre a Língua Brasileira de Sinais - LIBRAS e dá outras providências, Decreto 5.626/05 Regulamenta a Lei 10.43602, que dispõe sobre a Língua Brasileira de Sinais - LIBRAS, aporte que assegura a presença do intérprete em sala de aula e o reconhecimento da Língua Brasileira de Sinais - LIBRAS, como língua materna dos surdos, e Lei 9.394/96 - Lei de Diretrizes e Bases da Educação Nacional garantindo que o acesso e a permanência das pessoas com necessidades educativas especiais aconteçam preferencialmente nas redes do ensino regular. A metodologia da pesquisa é de caráter bibliográfico feito a partir de levantamentos de REFERÊNCIAS teóricas já analisadas, e publicadas por meios escritos, livros, e artigos científicos, permitindo conhecer o que já se estudou sobre o assunto. Faz-se ao final, relevantes considerações ao invés de uma conclusão, devido à amplitude do tema e a pesquisa contínua sobre este, para o desenvolvimento de uma educação de qualidade. Portanto, superar as diferenças de estrutura entre as línguas portuguesa e de sinais constitui um desafio importante no ensino do português para alunos surdos. Fica evidente que quanto maior a influência de alunos e professores na Língua de Sinais maiores as possibilidades de aprendizagem do português por esses alunos. Os resultados mostram também que apesar de serem oferecidas condições para um ensino de Língua Portuguesa escrita como L2, na prática, os professores ainda encontram dificuldades na compreensão dos textos e em uma forma de avaliação que não prejudique o desempenho escolar do aluno surdo.
\end{abstract}

Palavras-chave: Língua de sinais, Surdo, Língua Portuguesa, metodologia, avaliação.

\section{EVALUATION OF LEARNING OF THE PORTUGUESE LANGUAGE WRITING FOR DEAF: A SCHOOL CHALLENGE}

\section{ABSTRACT}

\footnotetext{
${ }^{1}$ Especialista em Libras pela Faculdade Internacional do Delta-FID.

Professora de Libras do Instituto Federal de Educação, Ciência e Tecnologia da Paraíba

Estudante do Curso de Graduação de Letras/Libras da Universidade Federal da Paraíba-UFPB Virtual

Graduada em Licenciatura Plena em História pela Universidade Federal da Paraíba-UFPB -

E-mail: agnesmarrocos@yahoo.com.br
} 
This article aims to discuss the written assessment of deaf students in Portuguese Language and the possible strategies used to ensure that this does not become a tool of exclusion, as well as meet and analyse the teaching practices of the Portuguese language for those students, explaining the possibilities and difficulties experienced in the teaching and learning process of the Portuguese Language for these students and their teachers. Being able to use possible methodologies, respecting and understanding the subject deaf and their different identities. Relevant aspects will be addressed on the education of the deaf in relation to assessment of the Portuguese Language in your writing mode, for the school development of deaf students. With the axis of the 1988 Federal Constitution which says that everyone has the right to education (Brazil, 1988), Law 10. 436/02 which Language Brasi Signal - Pounds Brazilian, as the mother tongue of the deaf, and the Law 9394/96 Law of National Education Bases and guidelines ensuring that the access and permanence of persons with special educational needs happen preferably in regular education networks. Makes to the end, relevant considerations rather than a conclusion, because of the breadth of the subject and the continuous research on this, for the development of a quality education. Therefore, to overcome the differences in structure between the Portuguese and signals constitutes a major challenge in teaching Portuguese to deaf students. It is clear that the larger the fluency of students and teachers in the language of signs.

Keywords: Sign Language. Deaf. Portuguese Language. Methodology. Evaluation.

\section{INTRODUÇÃO}

Encontrar um método ideal para que pessoas surdas consigam escrever, seguindo as normas da Língua Portuguesa, tem suscitado incontáveis discussões entre estudiosos do ramo. Pois, a aquisição da Língua Portuguesa na modalidade escrita pelos alunos surdos tem sido motivo de discussão e preocupação para professores que trabalham com esses alunos em processo de inclusão. Várias estratégias metodológicas são utilizadas na produção de textos escritos e, também, em relação aos critérios que devem ser considerados no momento da avaliação desses alunos.

Esse artigo tem como objetivo a discussão da avaliação da escrita de alunos surdos na Língua Portuguesa e as possíveis estratégias utilizadas para que esta não se torne uma ferramenta de exclusão.

Para tanto, são objetivos específicos, como também conhecer, e apresentar o que diz a legislação brasileira sobre o ensino da Língua Portuguesa, bem como analisar algumas práticas de ensino da Língua Portuguesa para esses alunos, explicitando as possibilidades e dificuldades vividas no processo de ensino e aprendizagem da Língua Portuguesa por estes alunos e seus professores, principalmente no que se refere à avaliação do texto escrito pelo surdo. Podendo o profissional da educação utilizar possíveis estratégias pedagógicas, respeitando e entendo o sujeito surdo e suas diferentes identidades.

RPI Revista de Pesquisa Interdisciplinar, Cajazeiras, v. 1, Ed. Especial, 178 - 190, set/dez. de 2016. 
Para a consecução desses objetivos, são abordados neste trabalho aspectos relevantes sobre a educação dos surdos em relação a avaliação da Língua Portuguesa em sua modalidade escrita, para o desenvolvimento escolar dos alunos surdos, tendo como eixo de pesquisa a Constituição Federal de 1988 a qual fala que todos tem direito a educação (Brasil, 1988), a Lei 10.436/02 que dispõe sobre a Língua Brasileira de Snais - LIBRAS e dá outras providências, o Decreto 5.626/05 regulamenta a Lei 10.436/02, que dispõe sobre a Língua Brasileira de Sinais - LIBRAS, aporte que assegura a presença do intérprete em sala de aula e o reconhecimento da Língua Brasileira de Sinais - LIBRAS, como língua materna dos surdos, e a lei $n^{\circ}$ 9.394/96 - Lei de Diretrizes e Bases da Educação Nacional garantindo que o acesso e a permanência das pessoas com necessidades educativas especiais aconteçam preferencialmente nas redes de ensino regular. Ainda quanto à avaliação e suas especificidades, aborda-se o seu objetivo no processo de ensino e aprendizagem e possíveis estratégias na avaliação do aluno surdo, utilizando como pesquisa REFERÊNCIAS bibliográficas de autores que estudam o tema como Hoffmann(2010), Quadros (2011), Brochado (2003), entre outros.

Faz-se ao final, relevantes considerações ao invés de uma conclusão, devido à amplitude do tema e a pesquisa contínua sobre este, para o desenvolvimento de uma educação de qualidade.

\section{Avaliação Da Escrita Do Surdo Em Língua Portuguesa A Partir Da Legislação Brasileira}

Para além do âmbito da legislação, a Língua de Sinais deve ser reconhecida e promovida para o uso da comunicação e interação no cotidiano da pessoa com surdez. A Língua de sinais se efetua a partir de uma política pública de valorização da construção de uma pessoa surda bilíngue, LIBRAS como primeira língua e a Língua Portuguesa como segunda língua na modalidade escrita. Desse modo, buscam-se meios legais para que a pessoa surda não possa ser excluída do direito de participar de ambientes sociais e educacionais. Para garantir o desenvolvimento deste sujeito o Estado deve disponibilizar o aprendizado da língua de sinais e a consequente a ascensão de sua identidade linguística e cultural da pessoa surda.

Em relação à Constituição Federal de 1988 podemos afirmar que enquanto conjunto de normas é praticamente um "manual de instruções" que garante direitos. Fala-se de Direitos RPI Revista de Pesquisa Interdisciplinar, Cajazeiras, v. 1, Ed. Especial, 178 - 190, set/dez. de 2016. 
Humanos em várias partes da constituição, direitos que possuímos pelo simples fato que somos humanos. No artigo $5^{\circ}$ da Constituição são assegurados os Direitos Fundamentais dos Indivíduos, sem diferença entre homens e mulheres no sentido em que todos tem o mesmo direito.

Um dos objetivos fundamentais da Constituição federal de 1988, assegura "promover o bem de todos, sem preconceitos de origem, raça, sexo, cor, idade e quaisquer outras formas de discriminação" (art. $3^{\circ}$, inciso IV). Define, no artigo 205, a educação como direito de todos, garantindo o pleno desenvolvimento da pessoa, o exercício da cidadania e a qualificação para o trabalho. No seu artigo 206, inciso I, estabelece a "igualdade de condições de acesso e permanência na escola" como um dos princípios para o ensino e garante, como dever do Estado, a oferta do atendimento educacional especializado, preferencialmente na rede regular de ensino (art. 208).

Como também a Constituição Federal (BRASIL, 1988), garante, no Art. 208, inciso III, o direito das pessoas com deficiência a estudar na rede regular de ensino.

Outras leis regem sobre o tema, como as comentadas a seguir:

\section{a) Lei no 9.394/96 - Lei de Diretrizes e Bases da Educação Nacional}

A atual Lei de Diretrizes e bases da Educação Nacional, Lei n ${ }^{\circ}$ 9.394/96, no artigo 59, declara que os sistemas de ensino devem assegurar aos alunos currículo, métodos, recursos e organização específicos para atender às suas necessidades; assegura a terminalidade especifica àqueles que não atingirem o nível exigido para a conclusão do ensino fundamental, em virtude de suas deficiências; e assegura a aceleração de estudos aos superdotados para conclusão do programa escolar. Também define as normas para organização da educação básica, a "possibilidade de avanço nos cursos e nas séries mediante verificação do aprendizado" (art. 24 inciso V) e "[...] oportunidades educacionais apropriadas, consideradas as características do alunado, seus interesses, condições de vida e de trabalho, mediante cursos e exames" (art. 37).

Em seu trecho mais controverso (art. 58 e seguintes), diz que "o atendimento educacional especializado será feito em classes, escolas ou serviços especializados, sempre que, em função das condições específicas dos alunos, não for possível a sua integração nas classes comuns de ensino regular".

RPI Revista de Pesquisa Interdisciplinar, Cajazeiras, v. 1, Ed. Especial, 178 - 190, set/dez. de 2016. 


\section{b) Lei $\mathrm{n}^{0} \mathbf{1 0 . 4 3 6 / 0 2}$}

A lei $n^{\circ} 10.436$ de 24 de Abril de 2002, no art. $1^{\circ}$ aborda que a Língua Brasileira de Sinais "é reconhecida como meio legal de comunicação e expressão e a outros recursos a ela associados", destacando em seu parágrafo único que entende como "Língua Brasileira de Sinais - LIBRAS, a forma de comunicação e expressão em que o sistema linguístico de natureza visual-motora com estrutura gramatical própria, constitui um sistema linguístico de transmissão de ideias e fatos oriundos de comunidades surdas".

Por conseguinte, no seu artigo $4^{\circ}$, parágrafo único, rege que "A Língua Brasileira de Sinais - Libras não poderá substituir a modalidade escrita da língua portuguesa.

\section{c) Lei $5.626 / 05$}

A metodologia bilíngue consiste em trabalhar com duas línguas no contexto escolar no que se refere a educação da pessoa com surdez, e neste caso em questão são a Língua Brasileira de Sinais e a Língua Portuguesa na modalidade escrita.

Garante o Decreto Lei 5.626/05 (BRASIL, 2005) em seu capítulo IV, artigo 14, o qual consta que se deve

\footnotetext{
VI - Adotar mecanismos de avaliação coerentes com aprendizado de segunda língua, na correção das provas escritas, valorizando o aspecto semântico e reconhecendo a singularidade linguística manifestada no aspecto formal da Língua Portuguesa.

VII - desenvolver e adotar mecanismos alternativos para avaliação de conhecimentos expressos em Libras, desde que devidamente registrados em vídeo ou com outros meios eletrônicos e tecnológicos.
}

O Decreto Federal $n^{\circ} 5.626$ de 22 de Dezembro de 2005, que regulamenta a Lei ${ }^{\circ}$ 10.436/02 que, por sua vez, dispõe sobre a Libras, estabelece que os alunos surdos devem ter uma educação bilíngüe, na qual a Libras deve ser considerada a primeira língua L1, e a Língua Portuguesa como L2 na modalidade escrita.

\section{O que dizem os especialistas sobre a escrita em segunda língua}

RPI Revista de Pesquisa Interdisciplinar, Cajazeiras, v. 1, Ed. Especial, 178 - 190, set/dez. de 2016. 
O ensino da Língua Portuguesa falada e escrita tem sido durante muito tempo objeto de estudo à medida que considera-se o fato de Língua Portuguesa ser a língua oficial e majoritária no nosso país e apresentar diversas nuances no que tange a prática da mesma em todos os âmbitos sociais e de educação em que um incontável número de filhos desta terra Brasil não domina sua própria língua, nem mesmo a falada como por conseguinte a escrita. $\mathrm{O}$ ensino da Língua Portuguesa para aqueles que ouvem e podem expressar-se oralmente já é motivo de discussões e polêmicas, desde sempre, o contrário não seria diferente. Referimonos aqui ao ensino e aprendizagem como também a avaliação da Língua Portuguesa escrita de surdos que ainda se apresenta como um universo "nebuloso" para alguns docentes.

Gutierres e Gama (1999, p. 86) acrescentam ainda que

\begin{abstract}
$\mathrm{Na}$ maioria dos casos, o aluno surdo, por ter a privação do sentido da audição, apresenta dificuldades na comunicação oral e gráfica, necessitando assim de um desprendimento de atenção por parte do professor um pouco maior em relação aos demais da classe, já que para os surdos, a Língua Portuguesa é um instrumento lingüístico que não se apresenta como recurso que vem facilitar o intercâmbio entre aluno e professor, mas um obstáculo que precisam transpor com grande dificuldade, pois, na maioria dos casos, a sua primeira língua do aluno surdo é a Língua Brasileira de Sinais (LIBRAS) e não a Língua Portuguesa.
\end{abstract}

Tomando como princípio o fato de que o processo ensino e aprendizagem de modo geral exigem muito daqueles que o fazem, e que ensino nem sempre implica aprendizagem efetiva, e considerando que desde sempre a educação escolar é alvo de controvérsias e mesmo de leis diversas que, às vezes, não são tomadas ao pé da letra, nem levadas em consideração no cotidiano escolar, e que nesse meio está à avaliação da aprendizagem não menos controversa e que, muitas vezes, é tratada como vilã em educação.

Se os procedimentos da avaliação estivessem articulados com o processo de ensinoaprendizagem propriamente dito, não haveria a possibilidade de dispor-se deles como se bem entende. No caso, a avaliação está muito mais articulada com a reprovação do que com a aprovação e daí vem a sua contribuição para a seletividade social, que já existe independente dela. (LUCKESI, 2006, p. 28)

O processo de inclusão de alunos surdos vai além do fato de inseri-los no ambiente escolar, pois o professor precisa conhecer e entender melhor a pessoa surda, sua língua e cultura para só assim poder incluir esse aluno e efetuar no seu cotidiano uma prática com o mínimo de inclusão e resultados.

RPI Revista de Pesquisa Interdisciplinar, Cajazeiras, v. 1, Ed. Especial, 178 - 190, set/dez. de 2016. 
Elaborar uma avaliação escolar que seja coerente e justa, e que vise reconhecimento da aprendizagem não é tarefa simples, e quando se trata da avaliação da escrita do português de alunos surdos e tem-se em mente o desejo de incluir e de não ser injusto ou desleal com os princípios éticos da prática educativa é necessário pensar o fazer pedagógico além de ser satisfatório para o processo de ensino e aprendizagem deve ser também humano, já que se trata de um grupo ou grupos de sujeitos quase sempre à margem devido a sua diferença num mundo de preconceitos múltiplos e excludente.

Hoffmann (2010, p.28) afirma que

\begin{abstract}
Além de estabelecer o que é, a avaliação implica estabelecer o que deve ser. Por conseguinte, a avaliação tem que responder a questão ética: o que deveríamos fazer? E a questão empírica: o que podemos fazer? Não basta desenvolvê-la a serviço da ação e como um projeto de futuro, mas tomar decisões educativas embasadas em considerações de valor, de política e filosofia social.
\end{abstract}

Dessa forma, na avaliação da aprendizagem do aluno surdo, não se pode permitir que o desempenho linguístico interfira de maneira tão negativa no desempenho escolar desses alunos que já possuem, por sua perda auditiva, um atraso linguístico no que se refere a Língua Português, seja falada ou escrita.

Então o professor deve levar em consideração as especificidades de cada aluno. Principalmente em relação aos surdos conhecer os aspectos que diferenciam dos outros alunos, respeitando-os e procurando construir um ambiente pedagógico que favoreça o desenvolvimento desse aluno.

[...] propomos que a avaliação do aproveitamento escolar seja praticada como uma contribuição de qualidade aos resultados da aprendizagem dos educandos, tendo por base seus aspectos essências e, como objetivo final, uma tomada de decisão que direcione o aprendizado e, consequentemente, o desenvolvimento do educando. (LUCKESI, 2006, p.95)

Sendo assim, o professor ao avaliar o conhecimento do aluno surdo não deve fazer com que os erros da estrutura formal da Língua Portuguesa superem o conteúdo. Não que este aluno permaneça no erro, mas, listá-los de forma que o professor junto ao educando possa superá-los, pois, duvidar que a aprendizagem não ocorreu baseando-se apenas no desempenho linguístico do aluno surdo, que é o ponto crucial de suas necessidades especiais, observando RPI Revista de Pesquisa Interdisciplinar, Cajazeiras, v. 1, Ed. Especial, 178 - 190, set/dez. de 2016. 
que "as habilidades a serem desenvolvidas pelo surdo incluem compreender e sinalizar sua língua, assim como ler e escrever na língua do seu país" (CAPOVILLA, 2002).

Deve salientar que a Língua brasileira de sinais (L1) e a Língua Portuguesa (L2) desempenham funções diferentes na vida dos surdos. A língua de sinais a como garantia do desenvolvimento da linguagem e do pensamento, enquanto que, a Língua Portuguesa possibilita que esses sujeitos façam valer seus direitos perante a sociedade ouvinte.

Conforme Carlos Skliar (2005, p.26)

Potencialidade como direito à aquisição e desenvolvimento da língua de sinais como primeira língua; potencialidade de identificação das crianças surdas com seus pares e com adultos surdos; potencialidade do desenvolvimento de estruturas e funções cognitivas visuais; potencialidade para uma vida comunitária e de desenvolvimento de processos culturais específicos; e, por último, a potencialidade da participação dos surdos no debate lingüístico, educacional, escolar, de cidadania.

Assim, é impossível não reconhecer que tão importante quanto é o aluno o professor e sua capacidade ou não de chegar a estes sujeitos despertando-lhes o desejo de aprender e descobrir suas potencialidades.

Avaliar em quaisquer circunstâncias será sempre uma tarefa que exigirá muito do professor, que deve-se fazer com clareza e pensar não só em avaliar o aluno, mas, avaliar-se a si próprio, ao seu trabalho e pesar os erros e acertos enquanto profissionais da educação. E que a avaliação não deve ser instrumento punitivo e nem de discriminação no ambiente escolar, cabe ao professor elaborar estratégias avaliativas de forma que perceba no aluno surdo suas potencialidades e vencer as dificuldades encontradas quando do aprendizado da Língua Portuguesa.

\section{Níveis de Interlíngua Brochado ( 2003)}

Argumenta-se que há duas razões para os textos dos surdos apresentarem forma singular quando comparadas a produções de textos de falantes nativos da língua portuguesa. A primeira razão é que a língua de sinais mobiliza as hipóteses na escrita do português pelo surdo e isso reflete em seus textos. Isto é, a língua de sinais organiza a lógica das ideias dos surdos que se reflete nos textos escritos pelos surdos.

RPI Revista de Pesquisa Interdisciplinar, Cajazeiras, v. 1, Ed. Especial, 178 - 190, set/dez. de 2016. 
Sobre a aquisição da segunda língua para alunos surdos, apresentam-se alguns pressupostos fundamentais Quadros et al (1997):

- O processamento cognitivo espacial especializados dos surdos;

- O potencial das relações visuais estabelecidas pelos surdos;

- $\quad$ A possibilidade de transferência da língua de sinais para o português;

- $\quad$ As diferenças nas modalidades das línguas no processo educacional;

- As diferenças dos papéis sociais e acadêmicos cumpridos por cada língua;

- As diferenças entre as relações que a comunidade surda estabelece com a escrita tendo em vista sua cultura;

- Um sistema de escrita alfabética diferente do sistema de escrita das línguas de sinais; e

- $\quad$ A inexistência do alfabeto manual, que representa uma relação visual com as letras usadas na escrita do português;

Sendo esse um aprendizado que passa por várias fases que vão sendo superadas com o tempo. Onde temos nesse percurso a língua materna como ponto de partida e a segunda língua como ponto de chegada que é denominado de interlíngua.

De acordo com Brochado (2002)

A segunda língua apresentará vários estágios de interlíngua, isto é, no processo de aquisição do português, os surdos apresentarão um sistema que não mais representa a primeira língua, mas que ainda não representa a língua alvo. Apesar disso, esses estágios da interlíngua apresentam características de um sistema linguístico com regras próprias e que vai em direção à segunda língua. Isto é, a interlíngua não é caótica e desorganizada, mas apresenta hipóteses e regras que começam a delinear outra língua que já não é mais a primeira língua daquele que está no processo de aquisição da segunda língua. Na produção textual dos alunos surdos, observa-se este processo.

E a segunda razão que justifica o fracasso dos alunos surdos na apropriação da leitura e da escrita em português é inadequação metodológica da escola. Então adotar uma avaliação diferenciada não significa relevar as dificuldades dos alunos, mas há um sujeito ativo construindo hipóteses e tentando dominar as regras do português. $\mathrm{O}$ professor que reconhece esse esforço e conhece as especificidades linguísticas de um processo de aquisição de segunda língua, adotará critérios de avaliação diferenciados.

RPI Revista de Pesquisa Interdisciplinar, Cajazeiras, v. 1, Ed. Especial, 178 - 190, set/dez. de 2016. 
Para o professor da disciplina faça a leitura da produção textual original do aluno surdo, ele precisa se despir da preocupação com a forma e buscar compreender os conceitos apresentados pelo aluno. Ele também pode ter contato direto com o aluno, para esclarecer algumas expressões utilizadas no texto que não foram compreendidas e, nesse momento, se certificar do êxito do aluno ao lidar com os conceitos trabalhados. Para isso, o professor poderá solicitar que o intérprete de língua de sinais intermedeie os esclarecimentos entre o professor e o aluno. (QUADROS; STUMPF; OLIVEIRA, 2011)

Pelo fato do professor desconhecer que o aluno surdo fala uma língua e escreve em outra, e que trabalham com surdos incluídos nas salas de aulas de ensino regular, não levam em consideração essa diferença linguística quando se confronta com um texto escrito pelo surdo.

Existem elementos usados na Língua Portuguesa falada e escrita tais como: artigos, conjunções proposições e, em alguns casos, certos tipos de verbos que não são sinalizados em libras, e também os tempos verbais. Dessa forma, é comum nos textos dos surdos encontrarmos frases na estrutura gramatical da Libras, isso acontece também com ouvintes que estão em fase de aquisição de uma segunda língua. Há sempre uma interferência da língua materna que é a língua de partida com a segunda língua que é a língua alvo. Isso ocorre porque são estágios intermediários do processo de aprendizagem de uma segunda língua, ou seja, estágios de interlínguas.

Brochado (2003, p. 309-310) analisa vários textos escritos por surdos e apresenta alguns elementos recorrentes observados nos diferentes níveis de interlíngua, conforme segue:

\section{Interlíngua 1}

- Predomínio de construções frasais sintéticas;

- Estrutura de frases muito semelhante à Língua Brasileira de sinais (L1), apresentando poucas características do Português (L2);

- Aparecimento de construções de frases na ordem SVO, mas maior quantidade de construções tipo tópico-comentário;

- Predomínio de palavras de conteúdo (substantivos, adjetivos, verbos);

- Falta ou inadequação de elementos funcionais (artigos, preposições, conjunções);

- Uso de verbos, preferencialmente, no infinitivo;

RPI Revista de Pesquisa Interdisciplinar, Cajazeiras, v. 1, Ed. Especial, 178 - 190, set/dez. de 2016. 
- Emprego eventual de verbos de ligação (ser, estar, ficar), e, às vezes, incorretamente;

- Uso de construções de frases tipo tópico-comentário, em quantidade, proporcionalmente maior, no estágio inicial da apropriação da L2;

- Falta de flexão dos nomes em gênero, número e grau;

- Pouca flexão verbal em pessoa, tempo e modo;

- Falta de marcas morfológicas;

- Uso de artigos, às vezes, sem adequação quanto ao uso;

- Pouco emprego de preposição e/ou de forma inadequada;

- Pouco uso de conjunção e sem consistência;

- Semanticamente, é possível estabelecer sentido para o texto.

\section{Interlíngua 2}

- Justa posição intensa de elementos da L1 e da L2;

- Estrutura da frase ora com características da Língua Brasileira de Sinais, ora com características da frase do Português;

- Frases e palavras justapostas confusas, não resultam em efeito de sentido comunicativo;

- Emprego de verbos no infinitivo e também flexionados;

- Emprego de palavras de conteúdo (substantivos, adjetivos e verbos);

- Às vezes, emprego de verbos de ligação com correção;

- Emprego de elementos funcionais, predominantemente, de modo inadequado;

- Emprego de artigos, algumas vezes concordando com os nomes que acompanham;

- Uso de algumas preposições, nem sempre adequado;

- Uso de conjunções, quase sempre inadequado;

- Inserção de muitos elementos do Português, numa sintaxe indefinida;

- Muitas vezes, não se consegue apreender o sentido do contexto, parcialmente ou totalmente, sem o apoio do conhecimento anterior da história ou do fato narrado.

\section{Interlíngua 3}

RPI Revista de Pesquisa Interdisciplinar, Cajazeiras, v. 1, Ed. Especial, 178 - 190, set/dez. de 2016. 
- Predomínio de estruturas frasais SVO;

- Aparecimento maior de estruturas complexas;

- Emprego maior de palavras funcionais (artigos, preposição, conjunção);

- Categorias funcionais empregadas, predominantemente, com adequação;

- Uso consistente de artigos definidos e, algumas vezes, do indefinido;

- Uso de preposições com mais acertos;

- Uso de algumas conjunções coordenativa aditiva (e), alternativa (ou), adversativa (mas), além da subordinativa condicional (se), causal e explicativa (porque), pronome relativo (que) e integrante (que);

- Flexão dos nomes, com consistência;

- Flexão verbal, com maior adequação;

- Marcas morfológicas de desinências nominais de gênero e de número;

- Desinências verbais de pessoa $\left(1^{\mathrm{a}}\right.$ e $3^{\mathrm{a}}$ pessoas $)$, de número $\left(1^{\mathrm{a}}\right.$ e $3^{\mathrm{a}}$ pessoas do singular e $1^{\mathrm{a}}$ pessoa do plural) e de tempo (presente e pretérito perfeito), com consistência;

- Emprego de verbos de ligação ser, estar e ficar com maior freqüência e correção.

A escrita de surdos em interlíngua apresenta características lexicais e gramaticais da língua que está aprendendo com a estrutura da sua língua materna. Assim a produção textual do surdo apresenta dificuldades de interpretação.

\section{Considerações Finais}

Portanto, superar as diferenças de estrutura entre as línguas portuguesa e de sinais constitui um desafio importante no ensino do português para alunos surdos. Fica evidente que quanto maior a fluência de alunos e professores na Língua de sinais maiores as possibilidades de aprendizagem do Português por esses alunos. Os resultados mostram também que apesar de serem oferecidas condições para um ensino de Língua Portuguesa escrita como L2, na prática, os professores ainda encontram dificuldades na compreensão dos textos e em uma forma de avaliação que não prejudique o desempenho escolar do aluno surdo. 


\section{REFERÊNCIAS}

BRASIL. Constituição (1988). Constituição da República Federativa do Brasil. Brasília, DF, Senado, 1998.

Lei 9.394, de 20 de Dezembro de 1996. Estabelece as Diretrizes e Bases da Educação Nacional. Brasília, DF, 1996.

Lei 10.436, de 24 de abril de 2002. Dispõe sobre a Língua Brasileira de SinaisLIBRAS e dá outras providências.

Decreto 5.626, de 22 de dezembro de 2005. Regulamenta a Lei no 10.436, de 24 de abril de 2002, que dispõe sobre a Língua Brasileira de Sinais-Libras, e o art. 18 da Lei no 10.098, de 19 de dezembro de 2000.

BROCHADO. S. M. D. A apropriação da escrita por crianças surdas usuárias da língua de sinais brasileira. Tese de Doutorado. Universidade Estadual Júlio de Mesquita Filho, UNESP, São Paulo, 2003.

CAPOVILLA. A. G. C.; CAPOVILLA, F. C. Educação da criança surda: o bilinguismo e o desafio da descontinuidade entre a língua de sinais e a escrita alfabética. Rev. Bras. Ed. Esp., Marília, Jul-Dez. V.8, n. 2, p. 127-156, 2002.

GUTTIERRES, C.; GAMA, M. R. Detecção tardia de deficiência auditiva em crianças com alteração de linguagem. Acta Awho. Vol. 18, 1999.

HOFFMANN, J. Avaliar para promover: as setas do caminho. Porto Alegre: Mediação, 2010.13 ed.

LUCKESI, Cipriano Carlos. Avaliação da aprendizagem escolar: estudo/proposições. 18 ed. São Paulo: Cortez, 2006.

QUADROS. R. M. de. Aquisição de L1 e L2: o contexto da pessoa surda. In Anais do seminário: Desafios e Possibilidades na Educação Bilíngue para surdos. 21 a 23 de Julho de 1997. P.70-87.

QUADROS, R. M.; STUMPF, M.; OLIVEIRA, J. “Avaliação de Surdos na Universidade. In: HEINING, Otília; FRONZA, Cática (Org.). Diálogos entre linguística e educação. V. 2. Blumenau: Edifurb, 2011.

SKLIAR, Carlos (Org.). A Surdez: um olhar sobre as diferenças. 3. Ed. Porto Alegre: Mediação, 2005. 